\title{
Intense physical activity is associated with cognitive performance in the elderly
}

\author{
BM Brown $n^{1,2,3}$, JJ Peiffer ${ }^{1,4}$, HR Sohrabi ${ }^{1,2,3}$, A Mondal ${ }^{1,3}$, VB Gupta ${ }^{1,3}$, SR Rainey-Smith ${ }^{1,3}$, K Taddei $^{1,3}$, S Burnham $^{5}$, \\ KA Ellis ${ }^{6,7,8}$, C Szoeke ${ }^{9}$, CL Masters $^{6}$, D Ames ${ }^{7,8}$, CC Rowe $^{10}$, RN Martins ${ }^{1,2,3}$ and the AIBL research group
}

Numerous studies have reported positive impacts of physical activity on cognitive function. However, the majority of these studies have utilised physical activity questionnaires or surveys, thus results may have been influenced by reporting biases. Through the objective measurement of routine levels of physical activity via actigraphy, we report a significant association between intensity, but not volume, of physical activity and cognitive functioning. A cohort of 217 participants (aged 60-89 years) wore an actigraphy unit for 7 consecutive days and underwent comprehensive neuropsychological assessment. The cohort was stratified into tertiles based on physical activity intensity. Compared with individuals in the lowest tertile of physical activity intensity, those in the highest tertile scored $9 \%, 9 \%, 6 \%$ and $21 \%$ higher on the digit span, digit symbol, Rey Complex Figure Test (RCFT) copy and Rey Figure Test 30-min recall test, respectively. Statistically, participants in the highest tertile of physical activity intensity performed significantly better on the following cognitive tasks: digit symbol, RCFT copy and verbal fluency test (all $\boldsymbol{P}<0.05$ ). The results indicate that intensity rather than quantity of physical activity may be more important in the association between physical activity and cognitive function.

Translational Psychiatry (2012) 2, e191; doi:10.1038/tp.2012.118; published online 20 November 2012

\section{Introduction}

It has been well documented that aging is accompanied by a gradual decline in cognitive function and increased risk of cognitive impairment. ${ }^{1}$ Numerous studies have reported that people engaging in regular physical activity have higher levels of cognitive function and decreased risk of cognitive decline ${ }^{2-4}$ For example, findings from a 6-month intervention trial demonstrated that physical activity improved cognitive function over an 18-month follow-up period. ${ }^{2}$ Furthermore, previous studies indicate that intensity of exercise is likely to be a key component contributing to the association between physical activity and cognition. ${ }^{5,6}$ Improved performance in numerous cognitive domains, including speed of processing, memory and mental flexibility has been observed in participants who reported greater intensity of physical activity. ${ }^{5}$

Although these previous findings are encouraging, methodological issues need to be addressed to gain a better insight into the underlying mechanisms by which increased physical activity intensity results in improved cognition. ${ }^{7}$ To obtain large and statistically robust sample sizes, most prior studies have utilised self-reported surveys or questionnaires to quantify activities and activity levels. ${ }^{3-5,8}$ These measurement techniques, although acceptable, ${ }^{9}$ can present limitations in the types of activities captured (that is, walking, cycling and so on) and introduce potential biases in terms of recall and reporting. ${ }^{10}$ To address this issue, a small number of studies have quantified physical activity levels using actigraphy; ${ }^{11,12}$ which is the measurement of physical activity through a device. Consistent with self-reported data, these studies indicate a positive relationship between objectively measured physical activity and cognitive functioning. ${ }^{11,12}$ Nevertheless, an association between objective measurement of intensity of physical activity and cognitive function is yet to be reported.

The objective of the current study was to examine the association between total physical activity and intensity of physical activity, measured by actigraphy, and cognitive functioning in a group of cognitively healthy older individuals.

\section{Materials and methods}

Participants. The participants for this study were selected from the $(n=1112)$ Australian Imaging, Biomarkers and Lifestyle (AIBL) Study cohort. ${ }^{13}$ Methods of recruitment, assessment, inclusion and exclusion criteria for the AIBL study have been detailed previously. ${ }^{13}$ Participants were chosen from the initial cohort based on their willingness to

\footnotetext{
${ }^{1}$ Centre of Excellence for Alzheimer's Disease Research \& Care, School of Medical Sciences, Edith Cowan University, Joondalup, WA, Australia; ${ }^{2}$ School of Psychiatry and Clinical Neurosciences, University of Western Australia, Nedlands, WA, Australia; ${ }^{3}$ The McCusker Alzheimer's Research Foundation (Hollywood Private Hospital), Hollywood Medical Centre, Nedlands, WA, Australia; ${ }^{4}$ School of Psychology and Exercise Science, Murdoch University, Murdoch, WA, Australia; ${ }^{5} \mathrm{CSIRO}$, Preventative Health Flagship, Mathematics, Informatics and Statistics, Floreat, WA, Australia; ${ }^{6}$ Mental Health Research Institute, The University of Melbourne, Parkville, VIC, Australia; ${ }^{7}$ National Ageing Research Institute, Parkville, VIC, Australia; ${ }^{8}$ Academic Unit for Psychiatry of Old Age, Department of Psychiatry, The University of Melbourne, St Vincent's Aged Psychiatry Service, St George's Hospital, Carlton, VIC, Australia; ${ }^{9}$ Department of Psychiatry, University of Melbourne, Carlton, VIC, Australia and ${ }^{10}$ Department of Nuclear Medicine \& Centre for PET, Austin Health, Heidelberg, VIC, Australia

Correspondence: Professor R Martins, Centre of Excellence for Alzheimer's Disease Research \& Care, School of Medical Sciences, Edith Cowan University, 270 Joondalup Drive, Joondalup 6027, WA, Australia.
}

E-mail: r.martins@ecu.edu.au

Keywords: Alzheimer's disease; cognition; exercise; physical activity

Received 12 June 2012; revised 12 September 2012; accepted 6 October 2012 
participate in the actigraphy sub-study (as indicated on their consent form). A total of 217 male and female participants aged 60 years and older were pseudo-randomly selected from cognitively healthy participants (as determined by a panel of clinicians) of the AIBL Perth site, Western Australia. All participants were provided with an information document describing the risks and benefits of their participation in this study and written informed consent was obtained before data collection. Ethical approval for this study was obtained from the participating institutions' ethics committees: Edith Cowan University and Hollywood Private Hospital.

Procedures. On the day of assessment, participants underwent a series of cognitive assessments (described in detail below), completed a health/demographics questionnaire, and provided a venous blood sample for the determination of Apolipoprotein E (APOE) $\varepsilon 4$ genotype. ${ }^{14}$ During this visit, participants were also fitted with an Actigraph monitor. Participants returned the equipment after 7 days from which Actigraph data were downloaded for later analysis.

Actigraphy. Actigraphy was performed using GT1M monitors from Actigraph (Pensacola, FL, USA). Participants wore the activity monitors for 7 consecutive days, mounted on adjustable waist bands. The Actigraph monitor collects and reports physical activity in the form of 'counts', which are the summation of the accelerations measured during each epoch period. The monitor has the ability to measure changes in acceleration 30 times each second, thus with the use of a 1 -min epoch, 1800 measurements were summed and the value ('count') recorded.

Participants were instructed to wear the monitors at all times during the 7-day period. The monitors were only removed for water activities and showering, as per the manufacturer's instructions. If individuals found that wearing the Actigraph unit impeded on their sleeping they were then instructed to remove the Actigraph while in bed. A standard 'waking' window was created, this being from 0600 hours to 2300 hours and only data from this 'awake' time were used as an objective measure of daily activity.

For each participant, the recorded counts were used to calculate two physical activity scores. The total counts variable is a summation of counts for each day, averaged over the 7 days. The peak counts score is a measure of intensity, and reflects the highest intensity (peak count) recorded for each day, averaged over the 7-day period. All data were visually inspected to ensure that erroneous data, due to hardware faults, were excluded $(n=4)$.

Cognitive assessment. The neuropsychological assessment included measures of general cognition, verbal memory, spatial memory, attention/executive function, and verbal fluency as briefly outlined below. The Mini Mental State Examination was used as an assessment of global cognitive functioning. ${ }^{15}$ The digit span task (from the Wechsler Adult Intelligence Scale, WAIS-III) was adapted to measure attention and concentration. Digit symbol coding, another subscale from the WAIS-III, was administered to measure attention, working memory and speed. ${ }^{16}$ For the assessment of verbal memory, we utilised the Logical Memory-I and II, derived from Wechsler. ${ }^{17}$ Another measure of verbal memory was the California Verbal Learning Test (CVLT-II). ${ }^{18}$ The CVLT-II measures immediate verbal recall and delayed verbal recall. The Rey Complex Figure Test $(\mathrm{RCFT})^{19}$ was used as a measure of visuospatial functioning, retrieval and recall abilities. The RCFT measurements used in this analysis included the copying of the complex figure followed by retrieval after $30 \mathrm{~min}$. Verbal fluency was measured with the administration of COWAT (Controlled Oral Word Association Task) word fluency task. ${ }^{20}$ The Stroop Test was used as a timed measure of attention and cognitive flexibility. ${ }^{21}$

Statistical analysis. All statistical analyses were performed using IBM SPSS Statistics 19 for Windows Vista (SPSS) or R version 2.1.4.2 (ref. 22). A $P$-value of 0.05 or smaller determined a significant result for all analyses. All $P$-values were adjusted for multiple comparisons using false discovery rate. ${ }^{23}$

Descriptive data analyses were undertaken to provide means, s.d. and percentages for the entire cohort as well as separate analysis for each peak count (physical activity intensity) tertile. For the evaluation of demographic variables for each tertile, assumed equal variance $t$-tests or one-way analysis of variance were performed for continuous data and chi-square $\left(\chi^{2}\right)$ for categorical data.

Both continuous actigraphy variables (total counts and peak counts) underwent square root transformation to achieve normal distribution. Linear regression analyses were used to determine the association between the transformed physical activity variables and cognitive function variables. The unadjusted linear regression measured the association between physical activity (independent variable) and cognitive functioning scores (dependent variable). The adjusted model was the same as the unadjusted, with the inclusion of age, gender, years of education (YOE), APOE $\varepsilon 4$ allele carriage, body mass index (BMI) and self-reported cardiovascular disease (CVD) as independent variables.

To further investigate the relationship between physical activity intensity and cognitive function, the peak count actigraphy variable was used to stratify the group into tertiles (intensity measured by peak counts; tertile 1 (T1), 1206-2869; tertile 2 (T2), 2877-3702; tertile 3 (T3), 3705-5789). Using the Freedson equation, these count ranges were converted to the more commonly used metabolic equivalent values (MET); T1 = 2.4-3.7, T2 = 3.7-4.4 and T3=4.4-6.0 (ref. 24). One-way analysis of variance, with Tukey's post-hoc analysis, was used to evaluate differences in mean cognitive scores across the tertiles (Table 3, Figure 1). Adjusted multivariate linear regression models were run (with age, gender and YOE entered as covariates) to produce adjusted means for the cognitive scores of each physical activity intensity tertile (Table 3, Figure 1).

\section{Results}

Participant demographics are highlighted in Table 1. The cohort had a mean age of $69.5 \pm 6.6$ years and was comprised of $54 \%$ females and $46 \%$ males. In all, $24 \%$ of participants were carriers of the APOE $\varepsilon 4$ allele, and $52 \%$ of the cohort 
a

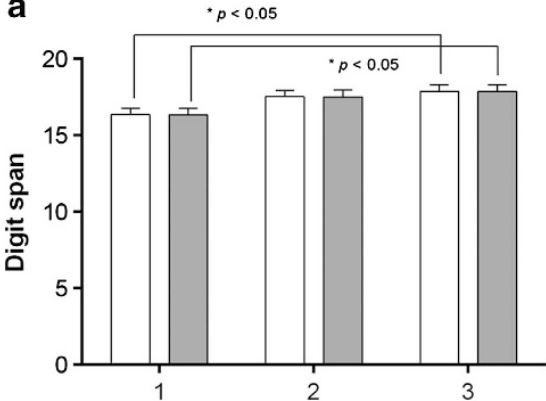

C

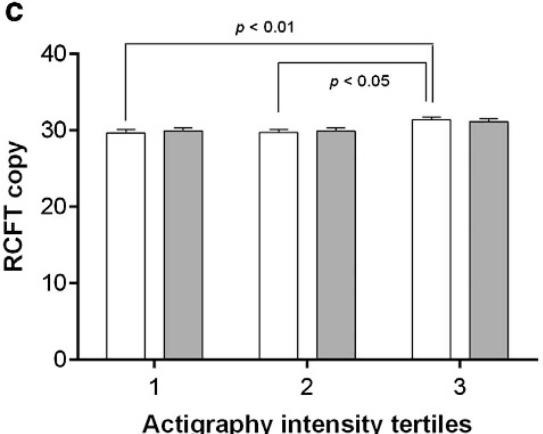

b

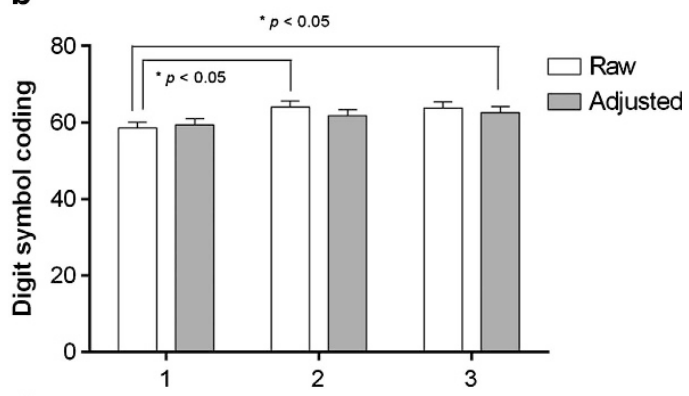

d

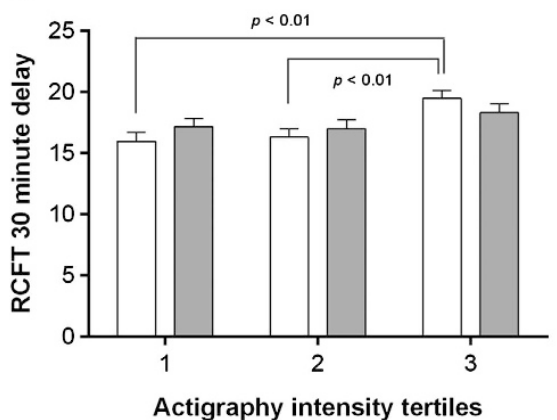

Figure 1 Those performing the most intense levels of physical activity (T3), performed better on digit span (a), digit symbol coding (b), RCFT copy (c) and RCFT 30-min recall (d), when compared with those performing the lowest intensity of physical activity (T1). Raw and adjusted (for age, gender and education) cognitive test score means $( \pm$ s.e.) for each actigraphy intensity tertile are displayed. $P$-values represent differences in raw means from one-way analysis of variance (post-hoc Tukey's) and multivariate linear regression for adjusted means. Tertiles: $1, n=72 ; 2, n=73 ; 3, n=72$. RCFT, Rey Complex Figure Test.

received more than 12 years of formal education. The average BMI was $26.1 \pm 3.8 \mathrm{~kg} \mathrm{~m}^{-2}$, and that of systolic blood pressure was $129.7 \pm 14.7 \mathrm{~mm} \mathrm{Hg}$. At baseline assessment, cardiovascular conditions were reported in $37 \%$ of participants. These diagnoses included hypertension (35\%), angina $(5 \%)$ and history of myocardial infarction (3\%). Participants with a history of symptomatic stroke were excluded from the study. Demographic differences across the peak count tertiles were assessed, and are also presented in Table 1. Those in T1 were significantly older $(F=15.08, P<0.001)$, had a higher mean $\mathrm{BMI}(F=6.32, P<0.01)$ and were more likely to have diabetes $\left(\chi^{2}=6.42, P<0.05\right)$ compared with those in T2 and T3. Tertile 2 had a higher proportion of females than T1 and T3 $\left(\chi^{2}=15.5, P<0.001\right)$. Participants in T3 were more likely to have received more than 12 YOE compared with $\mathrm{T} 1$ and T2 $\left(\chi^{2}=7.05, P<0.05\right)$.

In the unadjusted linear regression model, higher levels of actigraphy total counts were associated with better performance on the digit symbol task $(\beta=0.20, P<0.01)$, RCFT copy $(\beta=0.18, \quad P<0.05)$, RCFT 30-min delayed recall ( $\beta=0.22, P<0.01$ ) (Table 2). After adjustment for potential confounding variables, there were no significant associations between actigraphy total counts and cognitive test scores.

Peak counts were significantly associated with numerous cognitive function assessment variables (Table 2). Significant positive associations were observed between peak counts and digit span $(\beta=0.19, \quad P<0.01)$, digit symbol coding $(\beta=0.19, \quad P<0.01), \quad$ CVLT learning score $(\beta=0.17$, $P<0.05)$, CVLT delayed recall $(\beta=0.14, P<0.05)$, RCFT copy $(\beta=0.22, \quad P<0.01)$, RCFT $30-$ min delayed recall
( $\beta=0.27, P<0.001)$ and COWAT verbal fluency $(\beta=0.17$, $P<0.05)$. After adjustment for age, gender, YOE, APOE $\varepsilon 4$ allele, BMI and CVD, significant positive associations remained between peak counts and; digit symbol coding $(\beta=0.19, \quad P<0.05)$, RCFT copy $(\beta=0.21, P<0.05)$ and COWAT verbal fluency $(\beta=0.20, P<0.05)$.

The cohort was stratified into tertiles based on intensity of physical activity, measured by actigraphy (results shown as peak counts; T1, 1206-2869; T2, 2877-3702; T3, 37055789). After splitting the cohort into tertiles, means were calculated for each of the following cognitive tasks; digit span, digit symbol coding, CVLT learning, RCFT copy, RCFT 30-min delayed recall and COWAT letter fluency (Table 3). One-way analysis of variance (with post-hoc Tukey's analysis) and multivariate linear regression were then run to evaluate the difference in the raw and adjusted mean cognitive test scores across peak count tertiles. For the digit span task, those in T3 performed better than those in T1 (Figure 1a). Similarly, in the digit symbol task, the mean scores of those in T2 and T3 were significantly higher than those in T1 (Figure 1b). Participants in T3 performed better on RCFT copy (Figure 1c) and RCFT 30-min delayed recall (Figure 1d), compared with those in T1 and T2. To adjust for potential confounders, a multivariate linear regression analysis was run and adjusted means were produced for each of the tertiles for the cognitive tasks (shown in Figure 1). The trend for cognitive test scores across the tertiles remained significant after adjustment for age, gender and YOE in the digit span task and RCFT copy $(P<0.05$, Table 3$)$. 
Table 1 Descriptive statistics for the cohort and gender subgroups

\begin{tabular}{|c|c|c|c|c|c|}
\hline & $\begin{array}{c}A / l \\
(\mathrm{n}=217)\end{array}$ & $\begin{array}{c}T 1 \\
(n=72)\end{array}$ & $\begin{array}{c}T 2 \\
(n=73)\end{array}$ & $\begin{array}{c}\text { T3 } \\
(n=72)\end{array}$ & P-values* \\
\hline $\begin{array}{l}\text { Age } \\
\text { Gender, \% female }\end{array}$ & $\begin{array}{l}69.5 \pm 6.6 \\
54(117)\end{array}$ & $\begin{array}{l}72.5 \pm 6.6 \\
51(37)\end{array}$ & $\begin{array}{l}68.8 \pm 6.6 \\
71(52)\end{array}$ & $\begin{array}{c}67.0 \pm 5.2 \\
39(28)\end{array}$ & $\begin{array}{l}<0.001 \\
<0.001\end{array}$ \\
\hline $\begin{array}{l}\text { Cardiovascular disease }{ }^{a} \%(n) \\
\text { Hypertension } \%(n) \\
\text { Angina } \%(n) \\
\text { Heart attack \% }(n)\end{array}$ & $\begin{aligned} & 37(79) \\
& 35(74) \\
& 5(11) \\
& 3(6)\end{aligned}$ & $\begin{array}{l}47(34) \\
42(30) \\
10(7) \\
6(4)\end{array}$ & $\begin{array}{c}33(24) \\
31(23) \\
4(3) \\
0(0)\end{array}$ & $\begin{array}{c}29(21) \\
29(21) \\
1(1) \\
3(2)\end{array}$ & $\begin{array}{l}0.06 \\
0.24 \\
0.07 \\
0.13\end{array}$ \\
\hline $\begin{array}{l}\text { Diabetes \% }(n) \\
\text { APOE }^{\mathrm{b}} \varepsilon 4 \text { carrier } \%(n) \\
\text { YOE }^{\mathrm{C}} \%>12 \text { years }(n) \\
\text { Alcohol consumption }(\mathrm{U} / \text { week) } \\
\text { Body mass index }\left(\mathrm{kg} \mathrm{m}^{-2}\right) \\
\text { Blood pressure (systolic, } \mathrm{mm} \mathrm{Hg}) \\
\left.\text { Blood pressure (diastolic, } \mathrm{mm} \mathrm{Hg}^{-2}\right)\end{array}$ & $\begin{array}{c}6(12) \\
24(51) \\
52(112) \\
6.6 \pm 7.0 \\
26.1 \pm 3.8 \\
129.7 \pm 14.7 \\
74.7 \pm 9.9\end{array}$ & $\begin{array}{c}11(8) \\
22(16) \\
49(35) \\
6.2 \pm 5.9 \\
27.4 \pm 4.3 \\
131.0 \pm 16.4 \\
73.2 \pm 10.3\end{array}$ & $\begin{array}{c}3(2) \\
26(19) \\
43(31) \\
6.5 \pm 5.6 \\
25.5 \pm 3.1 \\
128.8 \pm 14.0 \\
75.4 \pm 9.9\end{array}$ & $\begin{array}{c}3(2) \\
26(19) \\
64(46) \\
7.3 \pm 6.5 \\
25.5 \pm 3.6 \\
128.8 \pm 14.1 \\
75.6 \pm 9.6\end{array}$ & $\begin{array}{l}0.04 \\
0.81 \\
0.03 \\
0.53 \\
0.002 \\
0.58 \\
0.27\end{array}$ \\
\hline
\end{tabular}

If not otherwise described, data are presented mean \pm s.d. of the mean.

${ }^{*} P$-values determined by independent samples $t$-test and one-way analysis of variance for continuous variables and chi-square for categorical variables.

a Medical history provided by participant self-report.

${ }^{\mathrm{b}} \mathrm{APOE}$, Apolipoprotein E (gene).

${ }^{\mathrm{C}} \mathrm{YOE}$, years of education.

Table 2 Unadjusted and adjusted ${ }^{\mathrm{a}}$ linear regression models; actigraphy total counts and peak counts and cognitive scores

\begin{tabular}{|c|c|c|c|c|}
\hline & \multicolumn{2}{|c|}{ Actigraphy total counts } & \multicolumn{2}{|c|}{ Actigraphy peak counts } \\
\hline & $\begin{array}{c}\text { Unadjusted } \\
\text { Standardised } \beta\end{array}$ & $\begin{array}{c}\text { Adjusted } \\
\text { Standardised } \beta\end{array}$ & $\begin{array}{c}\text { Unadjusted } \\
\text { Standardised } \beta\end{array}$ & $\begin{array}{c}\text { Adjusted } \\
\text { Standardised } \beta\end{array}$ \\
\hline MMSE $^{\mathrm{b}}$ & 0.05 & 0.04 & 0.10 & 0.12 \\
\hline Digit span & 0.07 & 0.02 & $0.19^{\star \star}$ & 0.16 \\
\hline Digit symbol coding & $0.20^{* *}$ & 0.18 & $0.19^{\star *}$ & $0.19^{\star}$ \\
\hline Logical memory II & 0.01 & -0.02 & 0.05 & 0.04 \\
\hline $\mathrm{CVLT}^{\mathrm{C}}$ learning score & 0.14 & 0.06 & $0.17^{\star}$ & 0.13 \\
\hline CVLT-II delayed & 0.12 & 0.06 & $0.14^{\star}$ & 0.12 \\
\hline RCFT $^{d}$ copy & $0.18^{*}$ & 0.15 & $0.22^{* *}$ & $0.21^{*}$ \\
\hline RCFT 30 min delay & $0.22^{\star \star}$ & 0.09 & $0.27^{\star \star \star}$ & 0.14 \\
\hline COWAT $^{\mathrm{e}}$ letter fluency & 0.10 & 0.10 & $0.17^{*}$ & $0.20^{*}$ \\
\hline Stroop—colours & -0.10 & -0.08 & -0.10 & -0.10 \\
\hline
\end{tabular}

${ }^{\star} P<0.05$.

${ }^{\star \star} P<0.01$.

${ }^{\star \star *} P<0.001$ ( $P$-values all adjusted for false discovery rate).

${ }^{a}$ Adjusted for age, gender, years of education, APOE $\varepsilon 4$ allele carriage, body mass index and cardiovascular disease.

bMMSE, Mini Mental State Examination.

${ }^{\mathrm{C}} \mathrm{CVLT}$, California Verbal Learning Test, Version 2.

${ }^{\mathrm{d}}$ RCFT, Rey Complex Figure Text.

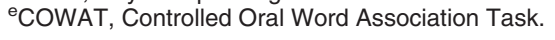

Table 3 Raw means ( \pm s.e.) of cognitive test scores across actigraphy intensity (peak count) tertiles. Analysis of variance and multivariate linear regression results

\begin{tabular}{|c|c|c|c|c|c|}
\hline \multirow[t]{2}{*}{ Cognitive Test } & \multicolumn{3}{|c|}{ Actigraphy intensity (peak count) tertiles } & \multirow[t]{2}{*}{$\mathrm{F}-$ value $^{\mathrm{a}}$} & \multirow{2}{*}{$\begin{array}{c}\text { Unstandardised } \beta \\
\text { coefficient }(95 \% \text { Cl) }\end{array}$} \\
\hline & $T 1$ & T2 & T3 & & \\
\hline $\begin{array}{l}\text { Digit span } \\
\text { Digit symbol/coding } \\
\text { RCFT copy }^{\mathrm{C}} \text { copy delay } \\
\text { RCFT } 30 \text { min dela } \text { CVLT }^{\mathrm{d}} \text { learning score } \\
\text { COWAT }^{\mathrm{e}} \text { letter fluency }\end{array}$ & $\begin{array}{l}16.4 \pm 3.38 \\
58.6 \pm 12.92 \\
29.7 \pm 0.5 \\
16.0 \pm 0.7 \\
51.1 \pm 1.4 \\
39.6 \pm 1.3\end{array}$ & $\begin{array}{l}17.5 \pm 3.5 \\
64.0 \pm 14.55 \\
29.7 \pm 0.4 \\
16.3 \pm 0.7 \\
53.2 \pm 1.3 \\
40.2 \pm 1.0\end{array}$ & $\begin{array}{l}17.9 \pm 3.68 \\
63.8 \pm 13.0 \\
31.4 \pm 0.3 \\
19.5 \pm 0.6 \\
55.2 \pm 1.3 \\
43.5 \pm 1.4\end{array}$ & $\begin{array}{l}3.66^{\star} \\
3.77^{\star} \\
5.75^{\star \star} \\
7.78^{\star \star \star} \\
2.26 \\
2.92\end{array}$ & $\begin{array}{c}0.656^{\star}(0.038,1.275) \\
1.743(-0.605,4.091) \\
0.574^{\star}(-0.042,1.190) \\
0.538(-0.438,1.514) \\
1.132(-0.630,2.895) \\
2.037^{\star}(0.212,3.934)\end{array}$ \\
\hline
\end{tabular}

${ }^{\star} P<0.05$.

${ }^{\star \star} P<0.01$.

${ }^{\star \star \star} P<0.001$.

${ }^{a} F$ value calculated from unadjusted one-way analysis of variance.

bUnstandardised coefficients from multivariate linear model adjusted for age, gender and years of education (95\% confidence interval).

${ }^{c}$ RCFT, Rey Complex Figure Test.

${ }^{\mathrm{d} C V L T}$, California Verbal Learning Test, version 2

${ }^{e}$ COWAT, Controlled Oral Word Assocation Task. 


\section{Discussion}

The purpose of the present study was to evaluate the relationship between cognitive functioning and both total volume and intensity of physical activity, measured by actigraphy, in a group of 217 older men and women. The main findings were: 1) physical activity intensity (peak counts), as measured by actigraphy, was associated with better performance on a range of cognitive assessment tasks; this association remained after adjustment for potential confounders for three of the cognitive tasks, and 2) total activity (total counts), measured by actigraphy, was associated with performance on various cognitive tasks, however this relationship was not evident after controlling for the effects of confounding variables.

In the current study, we observed significant positive associations between higher intensity physical activity and scores on the digit symbol, RCFT copy and COWAT verbal fluency tests (Table 2), with these associations remaining after controlling for confounding factors. Our findings are in agreement with previous research, which has shown intensity of physical activity can positively influence cognitive ability. ${ }^{5,6,25}$ For instance, both Laurin et al. ${ }^{25}$ and van Gelder et $a .^{6}{ }^{6}$ reported an increase in the intensity of self-reported physical activity over a follow-up period (5 and 10 years, respectively) was associated with slower decline in cognitive functioning. Additionally, Angevaren et al. ${ }^{5}$ observed better performance on cognitive tasks assessing speed, memory, mental flexibility as well as higher global cognition scores, in individuals with higher self-reported physical activity intensities. Together, these findings indicate that intensity of physical activity has a significant influence on cognitive ability. Ours is the first study to report an association between actigraphymeasured intensity of physical activity and cognitive function.

Total activity levels, when unadjusted for confounding factors, were associated with visuospatial function and memory, attention, executive function and working memory (Table 2). However, when adjusted for confounding variables, such as age, gender, education, APOE \&4 allele carriage, CVD and BMI, these significant associations were no longer evident. These findings are contradictory to previous research that reported positive associations between objectively measured total activity and performance in a wide range of cognitive domains, such as memory, speed, executive function, visuospatial function, as well as measures of global cognitive functioning, ${ }^{11,12}$ even after controlling for confounding variables. The differences in our results are possibly due to the demographic qualities of our group. For example, compared with our cohort (mean age 69 years) the group of individuals examined by Buchman et al. ${ }^{12}$ and Barnes et al. ${ }^{11}$ (82 and 83 years, respectively) were much older. As cognitive decline is associated with age, ${ }^{1}$ cognitive differences in a clinically non-demented cohort would be more apparent in an older population. Additionally, our cohort was an equal mix of males and females (54\% female) compared with Buchman et al. ${ }^{12}$ (77\% female), and Barnes et al. ${ }^{11}$ (100\% female), which may suggest a gender-dependent response to physical activity, however, this was not apparent in the current study. Compared with these prior studies, our comparatively smaller cohort size may also explain the non-significant results reported in this study.
Although the current study was not mechanistic in nature, it is important to theorise possible explanations for our findings to further future research in this field. First, intense physical activity can enhance cardiovascular health, as indicated by reductions in blood pressure and cholesterol levels. ${ }^{26}$ These changes have previously been associated with better cognitive function and reduced Alzheimer's disease risk. ${ }^{27,28}$ Second, high-intensity physical activity can enhance cardiovascular function, which can result in increased cerebral blood flow and perfusion, ultimately enhancing oxygen transport to the brain. ${ }^{29}$ Nevertheless, in the current study, CVD was used as a confounding variable in our analysis, with no influence on our results. This finding indicates that in this particular group of individuals, CVD may not wholly explain the relationship between physical activity intensity and cognitive functioning.

A large body of relevant experimental animal research has provided insight into the possible mechanism(s) responsible for the association between volume of physical activity and cognition. ${ }^{30,31}$ For instance, an increase in brain-derived neurotrophic factor was observed in the hippocampal neurons of rats exposed to exercise, indicating a neuroprotective effect of physical activity. ${ }^{32-35}$ It has also been suggested that brain-derived neurotrophic factor enhances hippocampal neurogenesis, the regulation of synaptic plasticity and neurotransmitter synthesis. ${ }^{36-38}$ Furthermore, in human subjects, engagement in a year-long physical activity intervention was associated with increased hippocampal volume (measured by magnetic resonance imaging). ${ }^{39}$ It is possible that these combined neuronal benefits enhance cognitive reserve, and thus protect against cognitive decline.

Neuro-degeneration, specifically in the pathology of Alzheimer's disease, is associated with the presence of amyloid- $\beta$ (A $\beta)$ plaques within the brain. ${ }^{40}$ In Alzheimer's disease transgenic mice, physical activity reduces $A \beta$ levels in the brain by reducing production of the peptide from its precursor-the amyloid precursor protein, or by increasing levels of neprilysin, an enzyme that degrades $A \beta$ peptides. ${ }^{41,42}$ More recently, in human cohorts, brain $A \beta$ imaging using positron emission tomography with $\left[{ }^{11} \mathrm{C}\right]$ Pittsburgh compound $\mathrm{B}$, has demonstrated lower amyloid loading in individuals who do greater amounts of exercise. ${ }^{43,44}$ It is likely that a combination of factors, including the discussed mechanisms together with currently unknown factors, mediate the positive effects of physical activity on cognitive function. Further research is required to determine whether these changes in biomarkers and neuronal processes are increased in response to more intense physical activity.

We acknowledge that there are certain limitations to the current study. The participants in this study were predominantly highly motivated and cognitively high-functioning individuals. Nevertheless, in an attempt to counteract the effects of surveying such a homogenous group, the neuropsychological battery contained a large selection of cognitive tests that should have been sensitive to cognitive differences, even in this high-performing cohort. Furthermore, this study was cross-sectional, and therefore the direction of the reported associations cannot be assumed. Indeed, it may be possible that better cognitive functioning leads an individual to partake in more intense physical activity. Further analysis 
using longitudinal data are required to fully understand the direction of this relationship.

In summary, men and women aged over 60 years, who performed more intense physical activity, as measured by actigraphy, performed better on tasks assessing cognitive function. This association existed independently of age, gender, education, APOE $\varepsilon 4$ allele carriage, BMI and CVD. Additional studies, in both human cohorts and animal models, are required to establish the optimum intensity of physical activity to receive maximum benefit to cognitive health.

\section{Conflict of interest}

The authors declare no conflict of interest.

Acknowledgements. BB is supported by a University Postgraduate Award from the University of Western Australia and a Freemasons' Western Australia Student Award. Core funding for this study was provided by CSIRO, which was supplemented by 'in kind' contributions from study partners. This research is supported by the Science and Industry Endowment Fund. The AIBL investigators thank Richard Head of CSIRO for initiating and facilitating the AIBL collaboration (http://www.aibl.csiro.au/). The study also received support from the National Health and Medical Research Council via the Dementia Collaborative Research Centres programme. Pfizer International has contributed financial support to assist with analysis of blood samples and to further the AIBL research programme. The McCusker Alzheimer's Research Foundation contributed financial and 'in kind' support to AIBL. We thank all those who took part as subjects in the study for their commitment and dedication to helping advance research into the early detection and causation of Alzheimer's disease.

1. Brayne C, Gill C, Paykel ES, Huppert F, O'Connor DW. Cognitive decline in an elderly population-a two wave study of change. Psychol Med 1995; 25: 673-683.

2. Lautenschlager NT, Cox KL, Flicker L, Foster JK, van Bockxmeer FM, Xiao J et al. Effect of physical activity on cognitive function in older adults at risk for Alzheimer disease: a randomized trial. JAMA 2008; 300: 1027-1037.

3. Middleton LE, Mitnitski A, Fallah N, Kirkland SA, Rockwood K. Changes in cognition and mortality in relation to exercise in late life: a population based study. PLOS One 2008; 3 : e3124.

4. Schuit AJ, Feskens EJ, Launer LJ, Kromhout D. Physical activity and cognitive decline, the role of the apolipoprotein e4 allele. Med Sci Sports Exerc 2001; 33: 772-777.

5. Angevaren M, Vanhees L, Wendel-Vos W, Verhaar HJ, Aufdemkampe G, Aleman A et al. Intensity, but not duration, of physical activities is related to cognitive function. Eur J Cardiovasc Prev Rehabil 2007; 14: 825-830.

6. van Gelder BM, Tijhuis MA, Kalmijn S, Giampaoli S, Nissinen A, Kromhout D. Physical activity in relation to cognitive decline in elderly men: the FINE Study. Neurology 2004; 63: 2316-2321.

7. Shephard RJ. Limits to the measurement of habitual physical activity by questionnaires. Br J Sports Med 2003; 37: 197-206.

8. Yaffe K, Barnes D, Nevitt M, Lui LY, Covinsky K. A prospective study of physical activity and cognitive decline in elderly women: women who walk. Arch Intern Med 2001; 161: 1703-1708.

9. Craig CL, Marshall AL, Sjostrom M, Bauman AE, Booth ML, Ainsworth BE et al. International physical activity questionnaire: 12-country reliability and validity. Med Sci Sports Exerc 2003; 35: 1381-1395.

10. Rzewnicki R, Vanden Auweele $Y$, De Bourdeaudhuij I. Addressing overreporting on the International Physical Activity Questionnaire (IPAQ) telephone survey with a population sample. Public Health Nutr 2003; 6: 299-305.

11. Barnes DE, Blackwell T, Stone KL, Goldman SE, Hillier T, Yaffe K. Cognition in older women: the importance of daytime movement. J Am Geriatr Soc 2008; 56: 1658-1664.

12. Buchman AS, Wilson RS, Bennett DA. Total daily activity is associated with cognition in older persons. Am J Geriatr Psychiatry 2008; 16: 697-701.

13. Ellis KA, Bush Al, Darby D, De Fazio D, Foster J, Hudson $P$ et al. The Australian Imaging, Biomarkers and Lifestyle (AIBL) study of aging: methodology and baseline characteristics of 1112 individuals recruited for a longitudinal study of Alzheimer's disease. Int Psychogeriatr 2009; 21: 672-687.

14. Hixson JE, Vernier DT. Restriction isotyping of human apolipoprotein $E$ by gene amplification and cleavage with Hhal. J Lipid Res 1990; 31: 545-548.

15. Folstein MF, Folstein SE, McHugh PR. "Mini-mental state". A practical method for grading the cognitive state of patients for the clinician. J Psychiatr Res 1975; 12: 189-198.
16. Weschler D. Weschler Adult Intelligence Scale, 3rd edn, (WAIS-III). The Psychological Corporation: San Antonio, TX, 1997.

17. Wechsler D. Wechlser Memory Scale, 3rd edn. Psychological Corporation: San Antonio, TX, 1997.

18. Delis DC, Kramer J, Kaplan E, Ober B. California Verbal Learning Test-Second Edition. The Psychological Corporation: San Antonio, TX, 2000.

19. Meyers Jeam KR. Rey Complex Figure Test and Recognition Trial: Professional Manual:: Psychological Assessment Resource, Inc, 1995.

20. Delis DC, Kaplan E, Kramer JH. The Delis-Kaplan Executive Function System (D-KEFS) Psychological Corporation: San Antonio, TX, 2001.

21. Strauss E, Sherman EMS, Spreen O. A Compendium of Neuropsychological Tests: Administration, Norms, and Commentary. 3rd edn, Oxford University Press: New York, 2006.

22. R Foundation for Statistical Computing. $\mathrm{R}$ Development Core Team $R$ : $A$ language and environment for statistical computing. Vienna, Austria, 2012.

23. Benjamini $Y$, Yekutieli $D$. The control of the false discovery rate in multiple testing under dependency. Ann Stat 2001; 29: 1165-1188.

24. Freedson PS, Melanson E, Sirard J. Calibration of the Computer Science and Applications, Inc. accelerometer. Med Sci Sports Exerc 1998; 30: 777-781.

25. Laurin D, Verreault $R$, Lindsay J, MacPherson K, Rockwood K. Physical activity and risk of cognitive impairment and dementia in elderly persons. Arch Neurol 2001; 58: 498-504.

26. National Institutes of Health. Physical activity and cardiovascular health. NIH Consensus Development Panel on Physical Activity and Cardiovascular Health. JAMA 1996; 276: 241-246.

27. Powell KE, Thompson PD, Caspersen CJ, Kendrick JS. Physical activity and the incidence of coronary heart disease. Annu Rev Public Health 1987; 8: 253-287.

28. Sparks DL, Martin TA, Gross DR, Hunsaker JC 3rd. Link between heart disease cholesterol, and Alzheimer's disease: a review. Microsc Res Tech 2000; 50: 287-290.

29. Colcombe SJ, Kramer AF, Erickson KI, Scalf P, McAuley E, Cohen NJ et al. Cardiovascular fitness, cortical plasticity, and aging. Proc Natl Acad Sci USA 2004; 101: 3316-3321.

30. Cotman CW, Berchtold NC. Exercise: a behavioral intervention to enhance brain health and plasticity. Trends Neurosci 2002; 25: 295-301.

31. Kramer AF, Erickson KI. Capitalizing on cortical plasticity: influence of physical activity on cognition and brain function. Trends Cogn Sci 2007; 11: 342-348.

32. Neeper SA, Gomez-Pinilla F, Choi J, Cotman C. Exercise and brain neurotrophins. Nature 1995; 373: 109

33. Neeper SA, Gomez-Pinilla F, Choi J, Cotman CW. Physical activity increases mRNA for brain-derived neurotrophic factor and nerve growth factor in rat brain. Brain Res 1996; 726: 49-56.

34. van Praag H, Christie BR, Sejnowski TJ, Gage FH. Running enhances neurogenesis, learning, and long-term potentiation in mice. Proc Natl Acad Sci USA 1999; 96: 13427-13431.

35. Adlard PA, Cotman CW. Voluntary exercise protects against stress-induced decreases in brain-derived neurotrophic factor protein expression. Neuroscience 2004; 124: 985-992.

36. Kermani P. Hempstead B. Brain-derived neurotrophic factor: a newly described mediator of angiogenesis. Trends Cardiovasc Med 2007; 17: 140-143.

37. Leibrock J, Lottspeich F, Hohn A, Hofer M, Hengerer B, Masiakowski P et al. Molecular cloning and expression of brain-derived neurotrophic factor. Nature 1989; 341: 149-152.

38. Vaynman S, Ying Z, Gomez-Pinilla F. Hippocampal BDNF mediates the efficacy of exercise on synaptic plasticity and cognition. Eur J Neurosci 2004; 20: 2580-2590.

39. Erickson KI, Voss MW, Prakash RS, Basak C, Szabo A, Chaddock L et al. Exercise training increases size of hippocampus and improves memory. Proc Natl Acad Sci USA 2011; 108: 3017-3022.

40. Masters CL, Simms G, Weinman NA, Multhaup G, McDonald BL, Beyreuther K. Amyloid plaque core protein in Alzheimer disease and Down syndrome. Proc Natl Acad Sci USA 1985; 82: 4245-4249.

41. Lazarov O, Robinson J, Tang YP, Hairston IS, Korade-Mirnics Z, Lee VM et al. Environmental enrichment reduces Abeta levels and amyloid deposition in transgenic mice. Cell 2005; 120: 701-713.

42. Adlard PA, Perreau VM, Pop V, Cotman CW. Voluntary exercise decreases amyloid load in a transgenic model of Alzheimer's disease. J Neurosci 2005; 25: 4217-4221.

43. Liang KY, Mintun MA, Fagan AM, Goate AM, Bugg JM, Holtzman DM et al. Exercise and Alzheimer's disease biomarkers in cognitively normal older adults. Ann Neurol 2010; 68 : 311-318.

44. Head D, Bugg JM, Goate AM, Fagan AM, Mintun MA, Benzinger T et al. Exercise engagement as a moderator of the effects of APOE genotype on amyloid deposition. Arch Neurol 2012.

Translational Psychiatry is an open-access journal published by Nature Publishing Group. This work is licensed under the Creative Commons Attribution-NonCommercial-No Derivative Works 3.0 Unported License. To view a copy of this license, visit http://creativecommons.org/licenses/by-nc-nd/3.0/ 